\title{
Relocalização de eventos com a rede temporária sob a Bacia do Parecis 2015
}

Bárbara Martins Rodrigues, George Sand França, Paulo Araújo de Azevedo

Observatório Sismológico, Universidade de Brasília

Copyright 2016, SBGf - Sociedade Brasileira de Geofísica

Este texto foi preparado para a apresentação no VII Simpósio Brasileiro de Geofísica, Ouro Preto, 25 a 27 de outubro de 2016. Seu conteúdo foi revisado pelo Comite Técnico do VII SimBGf, mas não necessariamente representa a opinião da SBGf ou de seus associados. É proibida a reprodução total ou parcial deste material para propósitos comerciais sem prévia autorização da SBGf.

\section{Resumo (Arial Bold, 9)}

Fonte: Arial normal, 9. Numero de palavras: cerca de 100.: Fonte: Arial normal, 9. Numero de palavras: cerca de 100. 100: Fonte: Arial normal, 9. Numero de palavras: cerca de 100.: Fonte: Arial normal, 9. Numero de palavras: cerca de 100.: Fonte: Arial normal, 9. Numero de palavras: cerca de 100.: Fonte: Arial normal, 9. Numero de palavras: cerca de 100.: Fonte: Arial normal, 9. Numero de palavras: cerca de 100.: Fonte: Arial

\section{Introdução}

Uma das regiões mais sismicamente ativa do Brasil está sob ou na borda da bacia do Parecis, em que o maior evento registrado no país aconteceu em 1955 com magnitude igual a 6.2. Em 2009, Barros et al. mostram a sismicidade para duas sequências sísmicas (1998 a 2002) e (2005) e também denominaram de Zona Sismogênica de Porto dos Gaúchos (ZSPG).

Atividade Sísmica na região da bacia do Parecis apresenta duas áreas que recebem destaque, à leste, uma zona sísmica orientada SW-NE que se estende deste a borda da bacia do Paraná até à fronteira da bacia do Parnaíba. Esta zona sísmica é sub paralela, mas não coincidente com o Lineamento Trans-Brasiliano, uma série de falhas do Neoproterozóico e do cambriano, coincidente com anomalias gravidade elevada ao longo da faixa de dobras Araguaia (Assumpção et al, 1986;. Fernandes et al., 1991). A outra zona está concentrada nas redondezas de Porto dos Gaúchos (ZSPG), com algumas sequências sísmicas estudadas por Barros et al. (2009) que mostraram um mecanismo transcorrente dextral orientado para ENE-WSW e sem correlação com o sistema de grábens e hosts sob a bacia.

A Bacia do Parecis é considerada uma das maiores bacias intracratônicas brasileiras, possuindo cerca de 500.000 km² de área. Localiza-se na região Amazônica, no centro oeste do Brasil, ocupando os estados de Rondônia e Mato Grosso, entre as bacias do Solimões e Paraná. A bacia é composta por $600 \mathrm{~m}$ de sedimentos paleozóicos, mesozóicos e cenozóicos, principalmente por siliciclásticos. Além da sequência sedimentar inclui rochas metamórficas de alto e baixo grau, rochas intrusivas básicas e ultrabásicas, kimberlitos, de idade mesozóica. Seu embasamento é o cráton Amazônico.

Segundo Siqueira, 1989, a Sub-bacia de Rondônia exibe dois grábens de direção geral E-W, Pimenta Bueno e Colorado. As principais deformações de média escala predominam nas zonas de falha, limites dos grábens Pimenta Bueno e Colorado, com brechas e silicificação (Braga \& Siqueira, 1996). Em zonas de fraqueza, implantou-se um sistema de riftes intracontinentais durante o evento extensional no Paleozóico (Bahia \& Pedreira, 2007; Siqueira, 1989). Sobre esse sistema de riftes se depositaram unidades litoestratigráficas, que geraram sequências deposicionais discordantes em nível regional. No interior da bacia há evidências da atuação de eventos tectônicos responsáveis por variações de suas fáceis e espessuras. (Siqueira \& Teixeira,1993).

Recentemente, através do projeto "Estudos tectônicos sobre a bacia do Parecis" financiado pelo CNPq, foram instaladas um conjunto de seis estações de banda larga com o objetivo de estudar a estrutura da parte central da bacia através da sismologia. Este trabalho pretende avaliar a qualidade desta rede utilizando eventos predeterminados pela Rede Sismográfica BRasileira (RSBR) e assim localizá-los com os dados obtidos através destas estações. A figura 1 mostra os eventos sísmicos utilizados neste trabalho, com a estimativa dada localização dada pela rede RSBR.

\section{Metodologia/ Problema Investigado}

O trabalho baseou-se em eventos locais, utilizando nove estações sismográficas de banda larga:, PAR1, PAR2, PAR3, PAR5, PAR6 (Rede Temporária), NPGB, PDRB, PTLB, e VILB (RSBR). Estes eventos ocorreram entre janeiro a dezembro de 2015, ao todo foram vinte e três eventos analisados, entretanto somente quatorze foram relocalizados. A figura 1 mostra as estações da Rede temporária em conjunto com as estações da RSBR e os eventos utilizados nesse estudo.

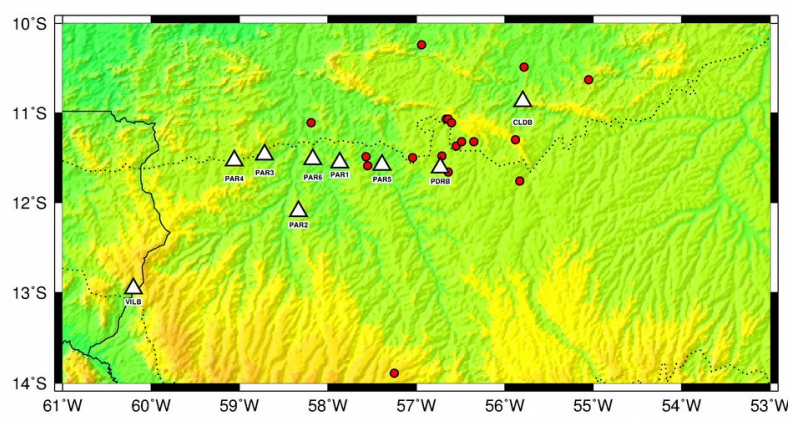

Figura 1 - Mapa de eventos sísmicos: círculos: Eventos utilizados; Triângulos: Estações utilizadas. As estações PAR1,PAR2,PAR3,PAR5,PAR6 pertencem a rede temporária e as demais a Rede Sismográfica Brasileira.

Dados sísmicos foram analisados através do software Seismic Analysis Code (SAC Goldstein \& Snoke, 2005), com a marcação das fases $\mathrm{P}$ e $\mathrm{S}$ (Figura 2). Para a obtenção das informações mais precisas dos eventos, 
INCLUIR AQUI O TITULO RESUMIDO (MÁXIMO DE 50 LETRAS. FONTE: ARIAL, 9)

calculamos a primeira estimativa usando programa elocate (Herrmann, 2013) e usando o modelo newBR (Assumpção et al. 2010). O modelo de velocidade é usado como uma base para estimar o comportamento da crosta em uma região, feito através de observações de eventos anteriores (velocidade das ondas $p$ e $s$ e a profundidade).

Em seguida aplicou-se a metodologia Jacknife, como aplicada pelo Primeto et al. (2007). A essência do procedimento é o de deixar sistematicamente uma observação de um conjunto de dados e depois os dados são invertidos até uma variância estabelecida.

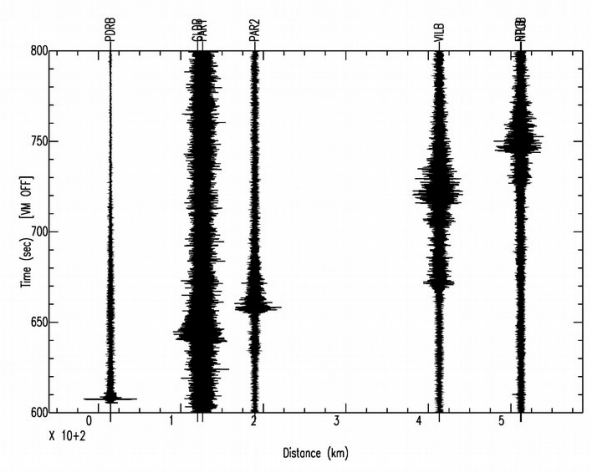

Figura 2 - exemplo de sismograma de um evento registrado pela rede temporária.

\section{Resultados}

$\mathrm{Na}$ tabela abaixo é observado os dados obtidos através da análise de fases dos sismos ocorridos na bacia. Primeiramente mostra o número de estações que foi analisada em cada evento e a localização estimada pelo boletim brasileiro. A estimativa usando o elocate $\mathrm{e}$ metodologia jacknife, obtendo a quantidade de estações usadas, a qualidade, o Resíduo Médio Quadrado (RMS) e o gab de cada evento para quantificar a qualidade dos resultados.

A maioria dos eventos estão nas latitudes e longitudes, em média -11 e -57, respectivamente, e grande parte dos eventos apresentam RMS menor que um. Os sismos que foram lidos em poucas estações também apresentam bons resultados, embora seja menos confiáveis.

\begin{tabular}{|c|c|c|c|c|c|c|c|c|}
\hline & & \multicolumn{2}{|c|}{ Catálogo } & \multicolumn{5}{|c|}{ jadknife } \\
\hline Eventos & estação & latitude & Iongitude & latitude & Iongitude & qualidade & RMS & gap \\
\hline 10/01/2015 06:55 & 3 & $-11,32$ & $-56,49$ & \begin{tabular}{|l|}
$-11,5329$ \\
\end{tabular} & $-56,8196$ & $\overline{B D}$ & 0,003 & 246 \\
\hline $26 / 01 / 201506: 12$ & $\overline{4}$ & $-11,37$ & $-56,55$ & $-11,6363$ & $-56,6423$ & $\overline{B D}$ & 0,007 & 201 \\
\hline $05 / 06 / 201523: 32$ & 7 & -11.48 & -56.71 & $-11,454$ & $-56,7742$ & $\mathrm{CC}$ & 0,194 & 161 \\
\hline $30 / 06 / 201500: 11$ & 4 & -11.11 & -58.19 & $-11,8723$ & $-57,8569$ & $\mathrm{DC}$ & 0,99 & 167 \\
\hline 30/10/2015 13:37 & 5 & -11.49 & -57.57 & -12 & -58 & $\mathrm{CC}$ & 0,014 & 164 \\
\hline $30 / 10 / 2015$ 14:03 & 3 & -11.59 & -57.55 & -11 & 669,48 & $\mathrm{DD}$ & 1,302 & 358 \\
\hline $06 / 11 / 201515: 49$ & 4 & -10.24 & -56.94 & -11 & $-56,264$ & $A D$ & $\overline{0}$ & 181 \\
\hline 14/11/2015 03:49 & 4 & -11.510 & -57.04 & -116.485 & -567.764 & $C D$ & 0,497 & 202 \\
\hline $22 / 11 / 201523: 50$ & 3 & -10.49 & -55.78 & $-10,415$ & $-56,0028$ & $\overline{A D}$ & 0 & 229 \\
\hline $15 / 12 / 2015$ 19:57 & 5 & $-11,66$ & $-56,64$ & $-11,6123$ & $-56,7296$ & $\overline{A D}$ & 0,002 & 201 \\
\hline
\end{tabular}

Tabela 1: Dados dos eventos estimados com a metodologia Jacknife

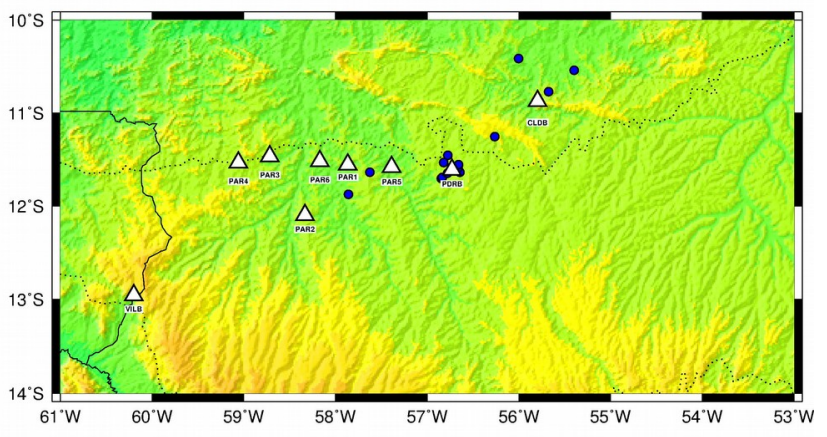

Figura 3 - Eventos relocalizados depois das leituras da rede temporária.

\section{Discussão e Conclusões}

As estações contribuiram para melhorar as estimativas, mostrando um que a dispersão dos eventos inicialmente não reflete a realidade, que em sua maioria parece está concentrada próxima a estação PDRB.

Como a implementação da Rede total somente em outubro de 2015, alguns eventos mantém o gap e um erro considerável.

A metodologia jacknife apresentou uma qualidade melhor que obtida pelo catalógo, entretanto não se pode confirmar se é devido o aumento de número de estações ou a prórpia metodologia.

O modelo newBR foi utlizado, como esse modelo foi estabelecido por eventos em sua maioria na parte central e sudeste do Brasil, pretende-se com o próximo testar modelos de velocidades que seja compatívelcom a região.

\section{Agradecimentos (Font: Arial Bold, 9)}

Aos Técnicos e Alunos de Campo, Daniel Linhares e Adriano pela implementação da rede temporária. Ao Pool de Equipamentoos, pelo empréstimo dos equipamentos, ao CNPq através do edital Universal 2014, processo 456560/2014-9 e GSF agradece ao CNPq/PQ.

\section{Referências}

Assumpção, M., Lima, T.M., Tomaz, L.A.R., 1986. O sismo de Araguapaz de 14/01/86 e o Lineamento Transbrasiliano. Proceedings, $34^{\circ}$ Congr. Bras. Geol., Goiânia/GO 6.

Assumpção o, M., Ardito, J., Barbosa, J.R., 2010. An improved velocity model for regional epicentre determination in Brazil. In: IV Simpósio Brasileiro de Geofísica, Brasília, 13 e16 de novembro de 2010.

Bahia, R.B.C., Martins-Neto, M.A., Barbosa, M.S.C., Pedreira, A.J., 2007. Análise da evolução tectonossedimentar da Bacia dos Parecis através de métodos potenciais. Rev. Bras. Geociênc. 37 (4), 639649.

Barros, L.V., Assumpção, M., Quintero, R., Caixeta, D.F., 2009. The intraplate Porto dos Gaúchos seismic zone in the Amazon craton e Brazil. Tectonophysics. 
Braga L.F.S. \& Siqueira L.P. 1996. Three dimensional gravity modelling of the basement topography beneath Parecis Basin, Brazil, constrained by spectral estimates of depth to magnetic sources. In: CONNEXPO/ARPEL.

GOLDSTEIN, P. \& A. SNOKE, 2005. "SAC Availability for the IRIS Community", Incorporated Research Institutionsfor Seismology Data Management System ElectronicNewsletter.

HERRMANN, R. B. (2013) Computer programs in seismology: An evolving tool for instruction and research, Seism. Res. Lettr. 84, 1081-1088, doi:10.1785/0220110096

Prieto et al. (04 co-authors), 2007. Confidence intervals for earthquake source parameters, Geophys. J. Int 168, 1227-1234. doi:10.1111/j.1365-246X.2006.03257.x

Siqueira L.P. 1989. Bacia dos Parecis. Boletim de Geociências da Petrobrás, 3:3-16.

Siqueira L.P. \& Teixeira L.B. 1993. Bacia dos Parecis: nova fronteira exploratória da Petrobrás. In: SBGeof., Congr. Intern. Soc. Brás. Geof., 3, Resumos Expandidos, p.168-170. 